\title{
A CONVERSA QUE DEVERIA EXISTIR: PMCMV E LUZ PARA TODOS
}

\author{
FARIA NETO, Alcyr de $M$. \\ PROARQ/UFRJ, e-mail: morisson@ufrj.br \\ ROLA, Sylvia $M$. \\ PPE/COPPE/UFRJ - PROARQ/UFRJ, e-mail: sylvia@ivig.coppe.ufrj.br \\ SILVA, Neilton F. \\ IFRN/PPE/COPPE/UFRJ, e-mail: neilton@ivig.coppe.ufrj.br
}

\begin{abstract}
RESUMO
O presente artigo vem discorrer sobre as relações dos agentes públicos governamentais nos programas "Luz para Todos" e Programa Nacional de Habitação Rural (PNHR). Inicialmente é mostrado os princípios, atuações, e análises de atividades sobre os programas, relacionando seus ápices de atuação. Verifica-se que a correlação entre eles se dá indiretamente, apesar dos mesmos terem em seus propósitos a inter-relação entre vários programas. Na análise em questão, pode-se notar que a relação do "Luz para Todos" com o PNHR se dá pela infraestrutura, causando a mesma restrição de contemplados, baseados no alto custo de implementação de logística dos interiores do nosso País.
\end{abstract}

Palavras-chave: Plano Nacional de Habitação Rural, Programa Luz Para Todos, Políticas Públicas.

\begin{abstract}
The current paper discusses about the relationships in Governmental Public Agents programs, "Luz Para Todos" and "Programa Nacional de Habitação Rural" (PNHR). Initially is show the programs principles, actions and activities analysis. Relating their apices is verified the indirect correlation between then, although they have in their purposes the relationship between several government programs. The relationship between "Luz para Todos" and PNHR comes providing infrastructure, with high cost of logistic implementation bringing a restrict kinds of contemplated users, the same happens with PNHR.
\end{abstract}

Keywords: Plano Nacional de Habitação Rural, Programa Luz Para Todos, Public Policy.

\section{INTRODUÇÃO}

As políticas de habitação do Governo Brasileiro, desde seu início com os Institutos de Aposentadoria e Pensões (IAPs), sempre tiveram como principal foco geográfico as áreas urbanas e suas proximidades, devido a facilidade de logística e baixo custo de infraestrutura em comparação com áreas rurais. Através da criação do INCRA em 1970 e o Estatuto da Terra (THEODORO, et al., 2017), iniciou-se a contribuição para a base do desenvolvimento legislativo da área Rural, porém acabou se desdobrando em uma concentração maior de terra nas mãos de latifundiários, já que as legislações visavam claramente o desenvolvimento capitalista da produção rural, excluindo assim os pequenos agricultores.

FARIA NETO, A. M.; ROLA, S. M.; SILVA, N. F. A conversa que deveria existir: PMCMV e luz para todos. In: SIMPÓSIO BRASILEIRO DE QUALIDADE DO PROJETO NO AMBIENTE CONSTRUÍDO, 6., 2019, Uberlândia. Anais... Uberlândia: PPGAU/FAUeD/UFU, 2019. p. $1-8 . \quad$ DOl https://doi.org/10.14393/sbqp19001. 
A discussão de reforma agrária a partir de 1984, com a redemocratização do País e o crescimento do Movimento dos trabalhadores Rurais Sem Terra (MST), trouxe à política pública a discussão dos assentamentos rurais, outrora posta a parte.

Em 2009 a Medida Provisória n 459/2009 e instituído pela Lei 11.977 de Julho de 2009, criou O Programa Minha Casa Minha Vida (PMCMV), O qual operacionaliza investimentos do Programa de Aceleração do Crescimento (PAC) para a construção de uma grande quantidade de moradias tanto urbanas quanto rurais, o que posteriormente veio se modificando em suas proporções devido aos altos custos de construção em locais mais afastados, priorizando mais uma vez as construções urbanas (CUNHA, 2018).

Paralelamente a este movimento, o Ministério de Minas e Energia vem desde 2003, através do Programa Luz para todos, trazendo às áreas Rurais e seus produtores, melhoria em suas condições de cidadania com auxilio para infraestrutura de escolas, hospitais, cooperativas de produtores e habitações dos mesmos, promovendo parcerias dentro de outros programas de Governo o Programa Nacional de Universalização do acesso e Uso da Energia Elétrica ${ }^{1}$ se mostra aberto e condizente com as categorias de auxilio propostos no PMCMV.

Este Artigo tem como objetivo traçar um paralelo entre os programas de auxílio a população rural do Minha Casa Minha Vida, o "Plano Nacional de Habitação Rural" e o "Luz para todos"

\section{BREVE HISTÓRICO DA HABITAÇÃO SOCIAL NO BRASIL}

É de competência comum da União, dos Estados, do Distrito Federal e dos Municípios: promover programas de construção de moradias e a melhoria das condições habitacionais e de saneamento básico. Art 23, parágrafo IX, Constituição Federal.

Segundo Bonduki (1994) os primeiros registros de moradias construídas com incentivos do Poder Público, data de 1906 no Rio de Janeiro, na Av. Salvador de Sá com 120 unidades habitacionais. A influência do Estado na produção habitacional brasileira começa em sua maior amplitude, no que tange a um programa de habitação e não somente um experimento isolado, com a criação das carteiras prediais dos Institutos de Aposentadoria e Pensões (IAPS) em 1937 e a Fundação da Casa Popular em 1946.

No período do Regime Militar no Brasil foi criado através da Lei. 4380 de 21 de agosto de 1964 o Sistema Financeiro de Habitação (SFH) e o Banco Nacional da Habitação (BNH), os quais fiscalizavam, regulamentavam e incentivavam os demais agentes nos desenvolvimentos da casa própria, o que perdurou até meados de 1990 (OLIVEIRA e KARNOPP, 2015).

Por um certo período os programas habitacionais de âmbito Federal, perderam a força com a retenção dos recursos da poupança criados pelo Plano Collor, criando uma retração nos investimentos imobiliários. Buscando um novo impulso no movimento econômico da construção civil, em 1990 foi lançado o Programa Brasileiro de Qualidade e Produtividade do Habitat

1 Portaria No 209/GM, de Maio de 2017 
(PBQP-Habitat'2), o qual tinha como premissa regular a qualidade do material, técnicas construtivas e índices de conformidades construtivas, para impulsionar a construção civil e regulamentar a habitação como processo de aquecimento econômico e geração de emprego e renda.

Em 2001 foi instituído o Estatuto das cidades para instrumentalizar a Política Habitacional Nacional, o que deu força para a criação, através da lei $n^{\circ}$ 10.683, de maio de 2003, do Programa de Arrendamento Residencial (PAR) e do Ministério das Cidades.

A partir de 2004, durante o governo Lula, deu-se uma forte retomada dos sistemas de produção de habitação de interesse social, o que veio sendo desenvolvido desde o governo Fernando Henrique Cardoso (FHC). O Programa Minha Casa Minha Vida (PMCMV) excluiu a participação popular do atualmente extinto Ministério das Cidades e suas decisões ficaram restritas entre a Casa Civil, o Ministério da Fazenda e os representantes do setor da Construção Civil (CUNHA, 2018).

Com a medida provisória $n^{\circ}$ 459/2009 e instituído pela lei 11.977, de 7 de julho de 2009 o PMCMV tem acesso a operacionalização e setorização dos investimentos do Programa de Aceleração do Crescimento (PAC) o que acelerou, de maneira ainda mais expressiva, a construção de diversas unidades habitacionais de interesse social pelo País.

\section{PROGRAMA MINHA CASA MINHA VIDA - MCMV}

O PMCMV foi criado para combater o déficit habitacional do Brasil, aquecendo a economia através da construção e financiamento de habitações de interesse social, utilizando algumas características de "modelo de negócio" do PAR (op cit.). As faixas de renda atendidas pelo programa, foram divididas em três, privilegiando as duas faixas de mais maior renda, faixa 2 e faixa 3 , as quais se mostravam mais lucrativas para a iniciativa privada do que a faixa de menor renda responsável por $85 \%$ do déficit habitacional, 0 que acabava por tornar as construções da faixa 1 o mais industrializadas possíveis para maior velocidade de execução e maximização de lucro das construtoras.

Internamente o programa era dividido em Plano Nacional de Habitação Urbana (PNHUR) e Plano nacional de Habitação Rural (PNHR), onde do período de maio de 2009 a maio de 2011, foi dado a mesma importância na questão dos repasses financeiros e metas de unidades de habitações urbanas e rurais, o que foi drasticamente alterado de junho de 2011 a junho de 2014 onde as metas de unidades de habitação rurais, caíram para apensa $3 \%$ do montante total (Quadro 1).

2 http://pbqp-h.cidades.gov.br/ 
Quadro 1. PMCMV: SUB-programas, linhas, fontes de recurso e metas físicas.

\begin{tabular}{|c|c|c|c|}
\hline \multicolumn{4}{|c|}{ PMCMV-1 - Maio de 2009 a maio de 2011} \\
\hline $\begin{array}{c}\text { Sub- } \\
\text { Programa }\end{array}$ & Linha & Fonte & Meta (unidades) \\
\hline PNHR & Grupo 1 (G-I): Renda até R\$ 15 mil/ano & OGU & \multirow{3}{*}{400.000 - Faixa $1(40 \%)$} \\
\hline \multirow{3}{*}{ PNHUR } & Empresas & FAR & \\
\hline & Entidades & FDS & \\
\hline & Financiamento Habitacional & FGTS & \multirow{3}{*}{$\begin{array}{l}400.000 \text { - Faixa } 2(40 \%) \\
200.000 \text { - Faixa } 3(20 \%)\end{array}$} \\
\hline \multirow{2}{*}{ PNHR } & Grupo 2 (G-II) - Renda entre $R \$ 15$ e $R \$ 30$ mil/ano & FGTS & \\
\hline & Grupo 3 (G-III) - Renda entre $R \$ 30$ mil e $R \$ 60$ mil/ano & FGTS & \\
\hline \multicolumn{3}{|r|}{ Total } & $1.000 .000(100 \%)$ \\
\hline \multicolumn{4}{|c|}{ PMCMV-2 - Junho de 2011 a dezembro de 2014} \\
\hline $\begin{array}{c}\text { Sub- } \\
\text { Programa }\end{array}$ & Linha & Fonte & Meta (unidades) \\
\hline \multirow{4}{*}{ PNHUR } & Empresas & FAR & 860.000 - Faixa $1(43 \%)$ \\
\hline & Entidades & FDS & $60.000-$ Faixa $1(3 \%)$ \\
\hline & Oferta pública & $\begin{array}{l}\text { Instituiçōes ou agentes } \\
\text { financeiros autorizados }\end{array}$ & 220.000 - Faixa $1(11 \%)$ \\
\hline & Financiamento Habitacional & FGTS & $\begin{array}{l}600.000 \text { - Faixa } 2(30 \%) \\
200.000 \text { - Faixa } 3(10 \%)\end{array}$ \\
\hline \multirow{3}{*}{ PNHR } & Grupo 1 (G-I) - Renda até R\$ 15 mil/ano & OGU & \multirow[t]{3}{*}{$60.000(3 \%)$} \\
\hline & Grupo 2 (G-II) - Renda entre $\mathrm{R} \$ 15$ e $\mathrm{R} \$ 30 \mathrm{mil} / \mathrm{ano}$ & FGTS & \\
\hline & Grupo 3 (G-III) - Renda entre $R \$ 30$ mil e $R \$ 60$ mil/ano & FGTS & \\
\hline & & Total & $2.000 .000(100 \%)$ \\
\hline
\end{tabular}

Fonte: Cunha, 2018

A habitação rural foi vista inicialmente pelo Governo, como parte integrante do Programa de Fortalecimento da Agricultura Familiar (PRONAF) desde 1995, e parte da melhoria da infraestrutura do trabalhador do campo, reafirmando a lei 8.171/91 de política agrícola que afirma no artigo 87 que: "É criada a política de habitação rural, cabendo a União destinar recursos financeiros para a construção e/ou recuperação da habitação rural."; e o Artigo 187 da constituição federal que define que:

"A política agrícola será planejada e executada na forma da lei, com a participação efetiva do setor de produção, envolvendo produtores e trabalhadores rurais, bem como dos setores de comercialização, de armazenamento e de transportes, levando em conta, especialmente: os instrumentos creditícios e fiscais; os preços compatíveis com os custos de produção e a garantia de comercialização; o incentivo à pesquisa e à tecnologia; a assistência técnica e extensão rural; o seguro agrícola; o cooperativismo; a eletrificação rural e irrigação; a habitação para o trabalhador rural."

O programa de Habitação Rural foi necessário (FAGUNDES, et al., 2013) para contemplar as especificidades de uma zona rural com logística, distâncias, culturas, climas, rendas e terrenos que tem características muito diferenciadas das zonas urbanas. O Manual do PNHR proposto pela CAIXA Econômica Federal (2012) enquadra como beneficiários: agricultores familiares; trabalhadores rurais; pescadores artesanais; extrativistas; silvicultores; aquicultores, piscicultores, maricultores; comunidades quilombolas; povos indígenas; e comunidades tradicionais; os quais apenas 
através de uma entidade organizadora, viabilizam junto a CAIXA a proposta de intervenção habitacional de no mínimo 4 e máximo 50 unidade habitacionais (U.H.) por proposta/projeto.

Ao contrário das Habitações Urbanas, no PNHR o proponente deve possuir a posse do lote/gleba contemplado, os mesmos já providos de soluções de abastecimento de água potável, esgoto sanitário e energia elétrica.

\section{O PROGRAMA LUZ PARA TODOS}

O Programa LUz para Todos (LPT) iniciou-se em 11 de novembro de 2003, através da lei 10.762, com o propósito de subsidiar a luz elétrica para dois milhões de habitações brasileiras focando principalmente nas zonas rurais e regiões mais distantes do país, onde o custo de implantação das concessionárias se tornava muito alto (CAMARGO e RIBEIRO, 2015).

O mesmo foi coordenado pelo Ministério de Minas e Energia (MME), Casa Civil, Ministérios de desenvolvimento agrário; Agricultura, Pecuária e Abastecimento; Desenvolvimento Social e Combate a fome; Integração Nacional; Educação; Saúde; Meio Ambiente; Ciência e Tecnologia; Indústria do desenvolvimento; e comercio Exterior. Com esta diversidade de poderes envolvidos, a programa contava e auxiliava vários outros programas de desenvolvimento rural implementados do Governo Federal.

Segundo o Manual de operacionalização do programa Nacional de Universalização do Acesso e Uso da Energia Elétrica, o Programa "Luz Para Todos" tem como seu público alvo atender as prioridades na seguinte ordem:

I - domicílios a serem beneficiados pelo Plano Brasil sem Miséria;

II - domicílios localizados nos Municípios participantes do Programa Territórios de cidadania;

III - domicílios localizados em assentamento rurais, comunidades indígenas, quilombolas e outras comunidades localizadas em reservas extrativistas ou em Áreas de Empreendimentos de Geração ou Transmissão de Energia Elétrica, cuja responsabilidade não seja do respectivo Concessionário;

IV - escolas, postos de saúde e poços de água comunitária;

$[\ldots]$

Camargo (2008) afirma que a eletrificação rural era socialmente excludente, onde 0 Estado privilegiava os interesses das concessionárias de energia elétrica. As mesmas diziam atender todos os solicitantes na forma da lei, a qual permitia que fossem cobrados do solicitante (o morador) a diferença entre 0 custo da obra e a eletrificação, o que poderia alcançar um montante absurdo tornando a implementação inviável para famílias que em geral ganhavam no máximo até 3 salários mínimos, visto que em 2003, no início do programa, o valor de implementação era de $\mathrm{R} \$ 257,92$ (duzentos e cinquenta e seta reais e noventa e dois centavos) e o salário mínimo era de $R \$ 240,00$ (duzentos e quarenta reais).

Em 2009 a foi atingida a meta de cerca de 10 milhões de pessoas na área rural, estendendo-se à 15,9 milhões de moradores das áreas rurais Brasileiras até novembro de 2016 principalmente nos assentamentos rurais, terras 
indígenas, territórios quilombolas e locais com grande presença de agricultores familiares (FREITAS e OLIVEIRA, 2017).

Segundo o MME (2017) partir de 30 de dezembro de 2014 o programa foi estendido apenas para contemplar cerca de 228 mil ligações já cadastradas e ainda pendentes. Este montante encontrava-se em localidades mais afastadas onde é inviável a extensão de redes convencionais e necessário a adoção de outras medidas de fornecimento de energia.

\section{CONSIDERAÇÕES FINAIS}

É importante ressaltar que nos dois programas governamentais, o perfil de usuários contemplados, necessariamente precisa estar envolvido com uma empresa, organizações não governamentais ou poder público, devido ao alto custo de implementação tanto da energia elétrica quanto das construções habitacionais em locais com difícil acesso, as concessionárias e construtoras, necessitam de uma garantia em volume de implementações e construções para viabilidade dos Programas.

Apesar da Casa Civil ser um ente federativo em comum entre os planos, Cunha (2018) e Camargo (2008) ressaltam que o interesse do Governo dentro dos planos tende a privilegiar as construtoras e concessionárias, o que pode sugerir o afastamento nas integrações pontuadas nos documentos oficiais dos programas aqui em questão.

Os dois programas tem seus picos de eficiência em períodos diferenciados, o Programa Luz para Todos de 2003 a 2009 e o Programa Nacional de Habitação Rural teve seu início logo após com pico de 2009 a 2013, porém pode-se observar que os contemplados com o PNHR, descritos na pouca bibliografia encontrada sobre $O$ assunto, estão relacionadas com comunidades tradicionais e cooperativas de agricultores, onde anteriormente foram contempladas com sistemas de infraestrutura governamentais.

A dificuldade de operacionalização das construções do PNHR (MARQUES, 2017) faz com que os projetos executados necessitem de apoio dos moradores, os que nem sempre são qualificados ou recebem treinamento adequado para auxiliar nas construções. Além do mais, no que diz respeito a eletrificação rural para questões de seleção através do senso (CAMARGO, RIBEIRO e GUERRA, 2008), só foram contemplados os moradores que não tinham realmente nenhum acesso à luz elétrica, aos que tinham 0 cabeamento vindos da vizinhança, instalação irregulares e que por ventura não tinham medidores, não poderiam ser contemplados, o que é um impeditivo para os critérios do PNHR.

Por fim, é sempre bom ressaltar que os sistemas de melhorias da cidadania propostos para os moradores do meio rural, esbarra na equação da viabilidade financeira e logística, necessitando uma melhor integração entre os programas governamentais para uma real universalização do exercício da cidadania.

\section{AGRADECIMENTOS}

A CAPES, pelo apoio recebido; 


\section{REFERÊNCIAS}

BONDUKI, N. G. Análise Social: Origens da Habitação Social no Brasil. Lisboa: [s.n.], v. Vol. XXIX (3. $\left.{ }^{\circ}\right), 1994.711-732$ p.

BRASIL. Decreto $n^{\circ} 7.520$, de 8/7/2011, alterados por Decretos $n^{\circ} 8.387$, de 30/12/2014 e $\mathbf{n}^{\circ} \mathbf{8 . 4 9 3}$, de 15/7/2015. Brasília: [s.n.], 2017. Disponível em: <https://WwW.mme.gov.br/luzparatodos/downloads/Manual_PLPT_Revisao_1_P ortaria_209.pdf>. Acesso em: jan. 2019.

Disponível em:

Constituição (1988). Brasília, DF: Presidência da República: [s.n.].

<http://www.senado.leg.br/atividade/const/con1988/con1988_06.06.2017/art_ 187_.asp>. Acesso em: 05 fev. 2019.

CAIXA. PROGRAMA NACIONAL DE HABITAÇÃO RURAL: Manual do Programa, Brasília, Fev. 2012.

CAMARGO, E. J. S. D.; RIBEIRO, F. S. Programa Luz Para Todos: Avanços e Retrocessos - Um novo estoque de excluídos. $10^{\circ}$ Congresso sobre Geração Distribuída e Energia no Meio Rural, São Paulo, 11 a 13 nov.2015.

CAMARGO, E.; RIBEIRO, F. S.; GUERRA, S. M. G. O Programa Luz Para Todos: Metas e Resultados. Espaço Energia, Curitiba, n 9, out. 2008.

CARTAXO, E. F.; COELHO, L. M. H. D. V.; PAIXÃO, V. Sustentabilidade do programa "Luz Para Todos" no Estado do Amazonas. Revista Brasileira de Energia, Rio de Janeiro, v. 12, n. 1, 2006.

CARVALHO, A. W. B. D.; PAULA, N. E. S. D.; PEREIRA, D. A. G. Programa Nacional de Habitação Rural e modo de morar no campo: reflexões a partir da casa rural na Zona da Mata mineira. PARANOÁ: Cadernos de Arquitetura e Urbanismo, Brasília, n. 17, 2016. ISSN 1679-0944.

COELHO, I. M. V.; CARTAXO, E. F. Universalização da Energia Elétrica: Uma Análise Política da distribuição de energia e da sua importância Socioambiental para o Amazonas. Procedings of the 5th Encontro de Energia no Meio Rural, 2004. Disponível em:

<http://www.proceedings.scielo.br/scielo.php?pid=MSC00000000220040002000 59\&script=sci_arttext>. Acesso em: 11 fev. 2019.

COSTA, S. B. O Programa Luz Para Todos: Uma política Pública de Inclusão Social. XIII - Mostra de Pós-graduação - UNITAU, Taubaté, out. 2012.

CUNHA, G. R. D. O programa Minha Casa Minha Vida: Estado, mercado, planejamento urbano e Habitação. ENANPARQ, Salvador, 2018.

FAGUNDES, J. R. et al. Análise das Metas do Programa Nacional de Habitação Rural (PNHR) no contexto Nacional. Revista do Desenvolvimento Regional FURB, Taquara/RS, v. 10, n. 2, jul/dez 2013.

FREITAS, G. D.; SILVEIRA, S. D. F. R. Programa Luz Para Todos: Uma Representação da Teoria do Programa através do Método Lógico. XXXVIII Encontro da ANPAD, Rio de Janeiro, jan. 2014.

FREITAS, G. F. D.; OLIVEIRA, M. L. R. D. Uma Análise do Programa Luz Para Todos do Governo Federal. Revista do Programa de Pós-Graduação em Extensão Rural (UFV), v. 6, n.2, jul./dez. 2017. ISSN Online: 2359-5116. 
MARQUES, A. S. PLANO NACIONAL DE HABITACÃO RURAL (PNHR) NO TERRITÓRIO QUILOMBOLA DE BOM JARDIM DA PRATA. $4^{\circ}$ FORUM HABITAR, Belo Horizonte, nov. 2017.

MME - MINISTÉRIO DE MINAS E ENERGIA. PROGRAMA NACIONAL DE UNIVERSALIZAÇÃO DO ACESSO E USO DA ENERGIA ELÉTRICA: Manual de Operacionalização para o período de 2015 a 2018 . Decreto n7.520 de 8/7/201 1, alterado pelos Decretos n'8.387, de 30/12/2014 e nº 8.493 de 15/7/2015, ANEXO À PORTARIA Nº 209/GM, DE 29 MAIO DE, 2017.

OLIVEIRA, A. D. Desempenho da implementação do Programa Luz Para Todos: Novos Atores como Fator Explicativo. Caderno Gestão Pública e Cidadania, São Paulo, v. 18, jul./dez. 2013.

OLIVEIRA, G. A. S. D.; KARNOPP, E. A POLÍTICA HABITACIONAL NO BRASIL E A HABITAÇÃO RURAL: um estudo preliminar sobre Santa Cruz do Sul, RS - Brasil. VII Seminário Internacional sobre desenvolvimento Regional, Santa Cruz do Sul/RS, 9 a 11 setembro 2015.

SOARES, P.; SILVA, M. L. P. D. A Utilização do instrumento de demarcação de área de especial interesse social em terrenos destinados a empreendimentos do Programa Minha Casa Minha Vida, o Caso do Município de Duque de Caxias. ENANPARQ, Salvador, 2018.

THEODORO, J. H. et al. Financiamento Habitacional no Campo: a sustentabilidade como problemática no desenvolvimento de edificações rurais. Caso do Distrito Federal. Paranoá: Cadernos de Arquitetura e Urbanismo, Brasília, n. 17, p. 14, fev. 2017. ISSN 1679-0944 